\title{
APPLICATION OF KEY PERFORMANCE INDICATORS FOR MAINTENANCE MANAGEMENT OF CLINICS FACILITIES
}

\author{
Igal M. SHOHET a,*, Lorenzo NOBILI a \\ a Department of Structural Engineering, Faculty of Engineering Sciences, Ben-Gurion University of \\ the Negev, P.O.B. 653, Beer Sheva, 84105, Israel
}

Received 18 March 2015; accepted 11 December 2015

\begin{abstract}
The investment in the development of the existing portfolio of clinics, as well as in their maintenance and operation, constitutes $3-4 \%$ of the annual budgets of health maintenance organizations (HMOs) in Israel. These clinics are the primary facilities for the provision of health services. The research objective was the implementation of previously defined key performance indicators (KPIs) in a 42 clinic sample in order to: (1) assess the maintenance performance of the facilities, (2) intra- and inter-benchmark the performance and efficiency, (3) establish a policy for the strategic and tactical maintenance management, and (4) set priorities in the maintenance plan. These actions should be part of a cycle for continuous improvement of the performance and maintenance of the facilities. This set of seven hybrid KPIs can be used for the leading and lagging analysis of the planning and control of facility maintenance. A case study is presented as an example of the applicability of the method.
\end{abstract}

KEYWORDS: Key performance indicators (KPIs); Life cycle costs (LCC); Maintenance; Outsourcing; Public sector

\section{INTRODUCTION}

The facilities available to the community health system enable it to provide medical services to the population and to have a significant impact on the quality of the service provided. The investment in the development of the existing portfolio of structures, as well as in their maintenance and operation, constitutes $3-4 \%$ of the annual budgets of the various health maintenance organizations (HMOs) in Israel. The facilities and their maintenance have significant implications for the quality of service and for the asset efficiency of the HMOs (Reiling et al. 2008; Ulrich, Quan 2004). Global and local trends have led to a shift in the concept of health service provision, away from the hospital as a principal provider of health services and towards the clinics (American Hospital Association 2010). The reason for this shift is the concept that the community health clinic should be the principal provider of health service to the population (Melin, Granath 2004). This global change is motivated by three main factors:

- A gradual and steady increase in the demand for health services;
- The need to improve the efficiency and effectiveness of the health system and to upgrade the management of its facilities;

- The increase in the capabilities of information and communication technologies (ICT) which permit multiple health services to be provided to distant locations.

The resultant modifications have shortened the duration of hospitalization, while increasing the number of in-patient admissions in community clinics (Statistics Denmark 2014; American Hospital Association 2014; Federal Statistical Office Germany 2014; Centraal Bureau voor de Statistiek 2014) culminating in intensive service conditions in community clinics. The quality of clinics strongly affects customer satisfaction; hence, comprehensive planning that takes into account life cycle costs (LCC) can be critical for effective clinic maintenance. The objectives of this research are to assess the reliability of a set of hybrid KPIs for assessing performance, and maintenance management, as well as for providing the basis for establishing the strategic and tactical policy of community clinics. 


\section{LITERATURE REVIEW}

The management and maintenance of facilities involve five core domains: maintenance, facility performance, risk management, development and upgrading of buildings, and facility management (Gallagher 1998; Gelnay 2002; Payne, Rees 1999). Organizations that own a large number of buildings and infrastructures require the consolidation of an integrated approach that will provide the facility managers with a systematic tool for facility management and maintenance during the design and construction stages and throughout the entire service life of the buildings and infrastructures. The integrated approach to maintenance is based on the concept that facility maintenance depends on organizational, engineering, functional, and economic factors and that optimal analysis and decision-making require the consideration of all of the above-mentioned factors in the process of facility maintenance (Shohet, Lavy 2004a).

The integrated approach to maintenance management comprises the following three basic elements (Shohet et al. 2003; Shohet, Lavy 2004b):

- The definition of indicators for the maintenance of buildings and infrastructures based on the portfolio of existing buildings and their classification according to categories of principal maintenance activities;

- Systematic evaluation of the state of the buildings and infrastructures based on defined scales of performance;

- Optimal allocation of resources to the maintenance work with the aim of achieving optimal performance and cost minimization.

There has recently been an increase in the number of organizations in both the private and the public sectors that outsource their non-core services (Kakabadse, A., Kakabadse, N. 2005; Yik, Lai 2005). In such cases, an analysis of the maintenance management must consider the relationship between the owner of the facilities and the contractor.

Ciarapica et al. (2008) pointed to four main reasons for the outsourcing of services that appear in the literature: the need to reduce costs and to increase efficiency; the need to focus on the core activities of the organization; the need to introduce greater workforce flexibility; and the need to decrease the power of the trade unions. The application of effective management methods such as outsourcing could facilitate the attainment of three important goals: high-performance maintenance, optimal management flexibility, and financial- economic efficiency. However, simply transferring the ownership of the facilities from the public to the private sector can achieve only limited results, and, in some cases, might even be counterproductive (Campbell 1995).

The owners of the facilities need to continue to control the performance of the non-core services in order to guarantee the support of the core business of the organization.

\subsection{Performance measurements}

In the field of facility management (FM) and maintenance, quantitative and qualitative criteria are used to examine the degree to which the objectives of assets are achieved in practice. In this process, actual performance is compared with accepted standards, or, alternatively, the management and maintenance of a specific structure are compared with those of a similar structure in accordance with performance indicators (PI). Examples of such criteria include the building performance indicator $(B P I)$, which measures the physical-functional state of a structure. Various studies in the professional literature have focused on the assessment of the maintenance performance. In an analysis of 40 Belgian industrial companies, Muchiri et al. (2010) reported a low level of satisfaction among maintenance managers; which was correlated to the low percentage of decisions based on the use of KPIs. This situation may be improved by a tight connection between different levels of maintenance management together with the application of a continuous cycle of performance measurementstrategy. In addition, as suggested by different authors (Campbell 1995; Amaratunga, Baldry 2002a, 2002b; Jones, Sharp 2007) maintenance indicators should be directly influenced by the maintenance objectives and needs of the organization; in these studies a low level of correlation between the KPIs used to measure performance and the objectives of the maintenance strategy was observed. These research studies illustrated shortcomings in the selection and use of KPIs. According to Lützkendorf et al. (2005) a building's performance needs to be measured, evaluated, and communicated in a standardized manner. The authors also established that it is possible to classify performance into categories as follows: technical performance, functional performance, social performance, economic performance, environmental performance, and process quality planning/operation.

According to Lavy et al. (2014a, 2014b), in order to effectively measure the performance of the 
building it is necessary to identify a set of KPIs specific for the facility under consideration with the requirement that these KPIs have to be: (1) quantifiable, (2) easily measurable, and (3) demonstrate wider applicability.

Grussing and Liu (2014) developed a method for the selection and scheduling of building component maintenance, repair and renovation activities, with the goal of the method being to minimize all related costs over a predetermined period of time, in accordance with the required performance and available resources. Two different indicators were used: a condition indicator (CI), which measures the level of physical deterioration and a capability index, which measures functional obsolescence due to age, changing standards, and changing performance requirements.

One of the issues noted by Jones and Sharp (2007) was the inability of performance models to predict the long-term cost of a building's maintenance. The various models that have been developed over the past decade for the prediction of the lifespan and maintenance needs of components often require a large amount of data, which is, in many cases, not available to facility managers.

Lavy et al. (2010) carried out a literature review on the performance indicators used for facility management. The authors grouped the performance indicators into four categories: financial indicators (costs and expenditures), physical indicators (the physical condition of the facility), functional indicators (the performance of the facility) and survey-based indicators (mainly qualitative indicators of user satisfaction). Their study reported that too many KPIs are referred to in the literature and identified three main issues: lack of applicability of the KPIs, lack of a holistic approach and improper categorization. Two reports (Lavy et al. 2010; Jones, Sharp 2007) highlighted the necessity for a set of KPIs which, are able to comprehensively assess the performance of a facility with a small amount of data.

Langston and Lauge-Kristensen (2002) defined three levels of maintenance management: strategic, tactical, and operational while Marquez and Gupta (2006) described the objectives for each level of maintenance management: to transform business priorities into maintenance priorities (strategic level); to determine the correct allocation of resources for the performance of maintenance (tactical level); and to ensure the proper execution of the maintenance work (operational level). Van Horenbeek and Pintelon (2014) suggested a bottom-up approach for the development of KPIs for each maintenance level in order to provide a global view of the performance of a facility. Such a global view would allow the maintenance manager to review the tactical and operational performance levels thereby revealing the root cause of any problems in the maintenance work or in its organization. A similar approach was used for the development of the BPI, through which one can arrive at a global view of the performance of a facility, review the performance of each system component $\left(P_{n}\right)$, identify any problems, and set up new maintenance priorities (Shohet 2003).

As stated above, one of the most important issues in the implementation of a performance measurement system is the alignment of maintenance objectives and the process of selecting the appropriate KPIs for the objectives of an organization (Campbell 1995; Amaratunga, Baldry 2002a, 2002b; Jones, Sharp 2007). Lavy et al. (2010) argued that the public or private nature of an organization influences the relevant type of performance measurement. For example, according to this approach, a public organization would favor performance measurements with a non-profit orientation.

In another example, Ciarapica et al. (2008) claimed that since the core business of the health sector is patient care, the objectives of such a facility maintenance should be represented by high continuity (availability) and a high level of functional safety, mainly related to the possible failure risks.

Jones and Sharp (2007) developed a model for the maintenance of built assets. The main issue addressed in their research study was the need to generate a maintenance strategy that could meet an organization's business requirements and generate income, rather than one based only on the physical condition of the assets. However, the application of this model to the public sector was found to be inadequate due to the particular nature of public organizations with a non-profit orientation (Ciarapica et al. 2008; Lavy et al. 2010). Thus, the adjustment of the priorities of maintenance work to an organization's goals should be carried out with reference to the level of outcome generated (in terms of performance of services).

\subsection{Healthcare facility and maintenance management}

The evolution of contemporary research in the field of maintenance management is currently displaying its most important and innovative 
developments in the industrial sector. Due to the high competitiveness of the market, industries tend to focus on the performance of noncore activities that could lead to an improvement in the availability and reliability of facilities as well as in increased corporate productivity. Few research studies to date have concentrated on maintenance management in the health sector. Some studies have analyzed the theme of hospital performance and maintenance, but only from a qualitative point of view (Gelnay 2002; Tulla et al. 2002; Cingolini et al. 2008; Stichler, Ecoff 2009; Talib et al. 2013; Islam et al. 2015). Other studies have investigated the management and maintenance of hospitals and have developed various key performance indicators (Pullen et al. 2000). However none of these considered the specific case of clinics.

Ali and Mohamad (2009) analyzed the existing facility maintenance management in hospital through a Malaysian hospital case study. The authors assessed five key elements namely: leadership; policies, plans and procedures; training and orientation; monitoring and supervision; and service performance. However, an analysis of the efficiency of the maintenance activities from an economic point of view and a comparison with other facilities in order to better analyze the shortcomings, are still missing.

Other research studies, such as the one carried out by Lega et al. (2013), focused on the performance of the supply chain management of health facilities, and the study conducted by Lennerts (2009) presented a comprehensive analysis of several hospitals in Germany, Switzerland and Luxemburg. Pati et al. (2010) developed a framework of hard and soft performance indicators for strategic maintenance planning in hospitals and courthouses.

\section{RESEARCH OBJECTIVES, METHOD AND PHASES}

\subsection{Research objectives}

The present research objective was to implement a set of clinic specific KPIs in a sample of 42 clinic facilities in Israel in order to: (1) assess the actual performance of the facilities, (2) intra- and inter-organization benchmarking, (3) establish the maintenance policy at the strategic and tactical level of management, and (4) set priorities for the maintenance plan.

\subsection{Research method}

The KPIs selected to assess the performance of the facilities were developed and used in previous studies where their capability of assessing the performance of maintenance services both from a strategic and tactical point of view was clearly demonstrated. In the present study, these KPIs were adapted to a clinic environment by redefining the systems and components constituting the building. Notably these changes affected the Building Performance Indicator, the Age Coefficient and the Density Coefficient.

Forty two clinics in Israel were selected in order to obtain a sufficiently comprehensive sample of different building features (age, size, location, and occupancy) to generate significant results.

Data were gathered through structured surveys conducted in each facility and interviews with facility managers/maintenance managers of the clinics.

Each clinic was analyzed with a view to benchmarking its performance and identifying possible improvements.

A representative case study taken from the clinic sample is presented in this paper in order to demonstrate the applicability of the KPIs and to clarify the method used for performance benchmarking, strategic planning and potential improvements of the maintenance and performance of the clinic. The selected KPIs refer to three major aspect of clinic FM: Development of the facilities (Age and Density Coefficients), Performance of the facilities (Building Performance Indicator and Maintenance Efficiency Indicator), and Maintenance (Annual Maintenance Expenditure, Maintenance Sources Ratio and Managerial Span of Control) as described below.

\subsection{Research phases}

The phases of the research are defined below:

Background for the theory:

- Definition of the KPIs for use in clinic facilities;

- Definition of the method for priority setting of the maintenance activities.

Application and findings:

- Performance assessment of the facilities;

- Intra- and inter-organization benchmarking;

- Statistical analysis of the results;

- Policy setting at the strategic and tactical levels of management;

- Definition of maintenance plan priorities. 


\section{THEORY BACKGROUND}

The present research study employed key performance indicators intended to monitor the performance and maintenance of clinics as follows:

- Age coefficient $\left(A C_{y}\right)$ of building;

- Density coefficient $\left(D C_{y}\right)$ of the clinic's patients;

- Building performance indicator $(B P I)$;

- Annual maintenance expenditure $\left(A M E_{y}\right)$;

- Maintenance efficiency indicator (MEI);

- Maintenance sources ratio (MSR);

- Managerial span of control (MSC).

The KPIs developed by Shohet and Lavy (2004a) were used to build a maintenance model of the building in accordance with life cycle principles (age coefficient and building performance indicator) in order to predict the evolution of maintenance costs for the entire lifespan of the building. The aim of these KPIs was not only to predict the maintenance needs of the various systems/components but also to provide the organization with a forecast of the maintenance expenditure during the lifespan of the clinic and to benchmark the performance of the different facilities. These performance indicators incorporate an evaluation of the maintenance work (MSC, MSR and $B P I)$ and of the outcomes of the maintenance work (BPI, MEI and AME); thus, these KPIs can be defined as hybrid indicators, both lagging and leading (Muchiri et al. 2011; Lavy et al. 2010). Figure 1 shows the adaptation of the performance measurement framework proposed by Muchiri et al. (2011) for the public sector in situations where there is an outsourcing of the maintenance activity (global service or partial outsourcing).

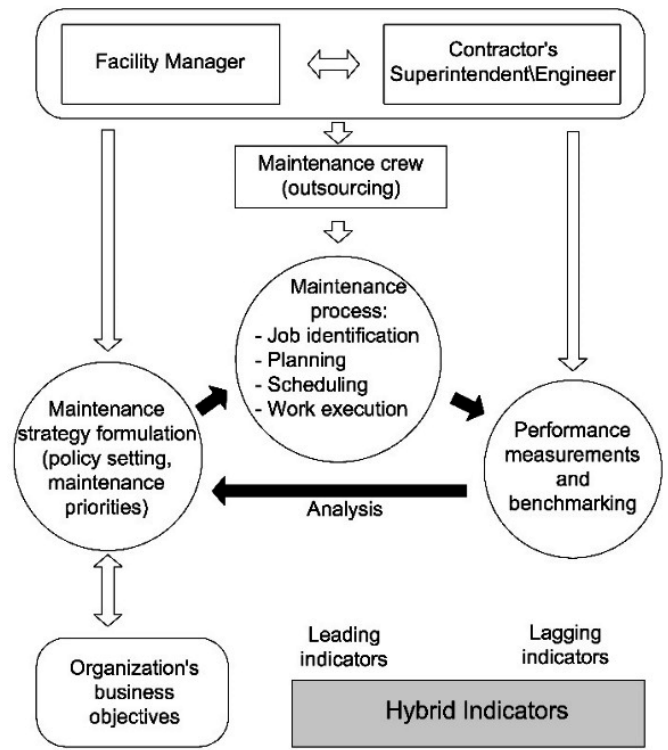

Fig. 1. Adaptation of the performance measurement framework proposed by Muchiri et al. (2011) for maintenance outsourcing in the public sector
In the proposed framework, the contractor's superintendent or engineer acts as an engineering consultant for the maintenance work (Straub, Van Mossel 2007; Straub 2009), and, in collaboration with the maintenance manager, defines the maintenance strategy that can meet the objectives of the organization. After the maintenance strategy has been determined (setting the maintenance policy at strategic and tactical level and defining the maintenance priorities) the process starts with maintenance job identification, proceeds to the planning and scheduling stages, and culminates in the execution of the maintenance work. After the maintenance work has been completed, the proposed KPIs are used to assess and benchmark the performance of the facility by the maintenance manager, who, together with the contractor's superintendent or engineer, defines possible improvements. In order to achieve a constant improvement of the efficiency and performance of the building, these three actions (maintenance work execution, performance measurement and benchmarking, and strategy definition) should be part of a continuous cycle. Once the performance has been assessed, this cycle begins again from the maintenance strategy formulation.

The following paragraphs describe the basic hypothesis and theory behind the core performance indicators.

\subsection{Key performance indicators}

\subsubsection{Annual maintenance expenditure (AME)}

This indicator reflects the maintenance expenditure per built square meter (excluding cleaning, energy, and security expenditures). From an organizational viewpoint, this indicator determines the annual expenditure on the maintenance of the clinics, and it can also provide a measure of the overall expenditure on the built assets in relation to the organization's turnover. From a managerial-professional viewpoint, however, the expenses must be analyzed with respect to the clinic's characteristics and output (the clinic's performance) as well as the service regime (annual number of visitors per annum $/ \mathrm{m}^{2}$ ).

\subsubsection{Age coefficient}

The age coefficient is defined as a coefficient for the adjustment of the maintenance needs to the actual service life of a facility. The calculation of coefficient for a clinic with a designed life cycle (DLC) of 50 years produced the following results: 
a value of 1 represents the average maintenance expenditure (2.5\% of reinstatement value) for the clinic's designed life cycle, the maximum value is $A C_{y}=1.6$ that occurs in the middle of the clinics' life cycle (refurbishment of electro-mechanical systems), whereas the lower values $A C_{y}=0.6-0.8$ occur in the first and last periods of the life cycle.

\subsubsection{Density coefficient}

The density coefficient reflects the effect of patient density on the deterioration of the clinic's components. Standard density was defined as 175 patients per $\mathrm{m}^{2}$ per annum and was defined as $100 \%$ density of patients. The values are calculated as follows:

- Under moderate density conditions (less or equal to $80 \%$ of standard density), the density coefficient is 0.97 , representing only minor savings in maintenance expenditures, because of the requirements of the clinic's mandatory preventive policy.

- When the relative density is between $80 \%$ and $100 \%$, the increase in maintenance activities is moderately linear.

- When the relative density is between 100\% and $154 \%$, patient density has a greater impact on maintenance expenditure, and the slope of the graph increases. With a relative density higher than $154 \%$ the density coefficient remains constant at a level of 1.31 .

\subsubsection{Building performance indicator (BPI)}

This indicator enables the evaluation of the overall state of the clinic or of the clinic portfolio, according to the performance of its components and systems. The indicator is defined by a value between 0 and 100, which expresses the physical state of the clinic, including the performance of its various systems $\left(P_{n}\right) . P_{n}$ is graded according to performance scales ranging from 0 to 100, where $P_{n}<60$ indicates a poor/dangerous performance condition, $60<P_{n} \leq 70$ indicates deteriorating performance, $70<P_{n} \leq 80$ indicates a marginal (70) or satisfactory (80) condition, and $P_{n}>80$ indicates a good performance condition. The score $P_{n}$ for each system is composed of three aspects of facility maintenance: the actual condition of the system $\left(C_{n}\right)$, failures affecting the service provided by the system $\left(F_{n}\right)$, and the actual preventive activities carried out on the system to maintain acceptable service level $\left(P M_{n}\right)$ (Israel Standards Institution 2010; Shohet 2003).

The $B P I$ is obtained by multiplying each system's weight by its score as shown in Equation (1).

$$
B P I=\sum_{n=1}^{10} P_{n} \times W_{n} .
$$

The desired $B P I$ range is $B P I>90$, although even at such a performance score, any system or component with a performance score of below 70 will require corrective maintenance measures.

This parameter enables: (1) evaluation of the overall state of a clinic (2) evaluation of the state of the clinic's systems (3) benchmarking the asset's performance in relation to other clinics or facilities (inter-organizational benchmarking) (4) benchmarking the clinic's systems in order to compare the efficiency of the various maintenance crews (intra-organizational benchmarking).

\subsubsection{Maintenance efficiency indicator (MEI)}

This indicator enables an examination of the investment in maintenance in relation to the clinic's performance (which is in fact the service provided to the health maintenance organization by the FM department).

The $M E I$ is calculated through Equation (2):

$$
M E I=\frac{A M E_{y}}{A C_{y}} \times \frac{1}{B P I} \times \frac{1}{D C_{y}} \times i_{c},
$$

where: $A M E_{y}$ is the actual annual maintenance expenditure for year $y ; A C_{y}$ is the age coefficient for year $y$; $B P I$ is the monitored building performance indicator; $D C_{y}$ is the density coefficient for the clinic in question; and $i_{c}$ is the construction prices index.

This indicator expresses the annual expenditure on maintenance per clinic performance unit, normalized by the use of both the age coefficient $\left(A C_{y}\right)$ and the density coefficient $\left(D C_{y}\right)$.

$M E I$ may be analyzed as the two-dimensional space of $B P I$ combined with normalized annual maintenance expenditure $\left(N A M E_{y}\right)$, as expressed in Equation (3):

$$
N A M E_{y}=\frac{A M E_{y}}{A C_{y} \times D C_{y}},
$$

where: $N A M E_{y}$ represents the annual maintenance expenditure neutralized from the effect of age $\left(A C_{y}\right)$, and from the clinic's patient density $\left(D C_{y}\right)$.

For a clinic maintained at a desired level, we assume a BPI of 100 . The average annual maintenance expenditure $\left(A M E_{y}\right)$ per $\mathrm{m}^{2}$ was assessed as $2.5 \%$ of the reinstatement value of a clinic facility which was calculated to be $\$ 1,180$ per built $\mathrm{m}^{2}$. For example, a clinic with an age coefficient of 1.00 (standard level), and a density coefficient of 1.00 would have an $M E I$ value of 0.30 . The upper and lower values of the desirable range were deduced from the standard deviation of the $M E I$ for the clinic sample population. The $M E I$ values 


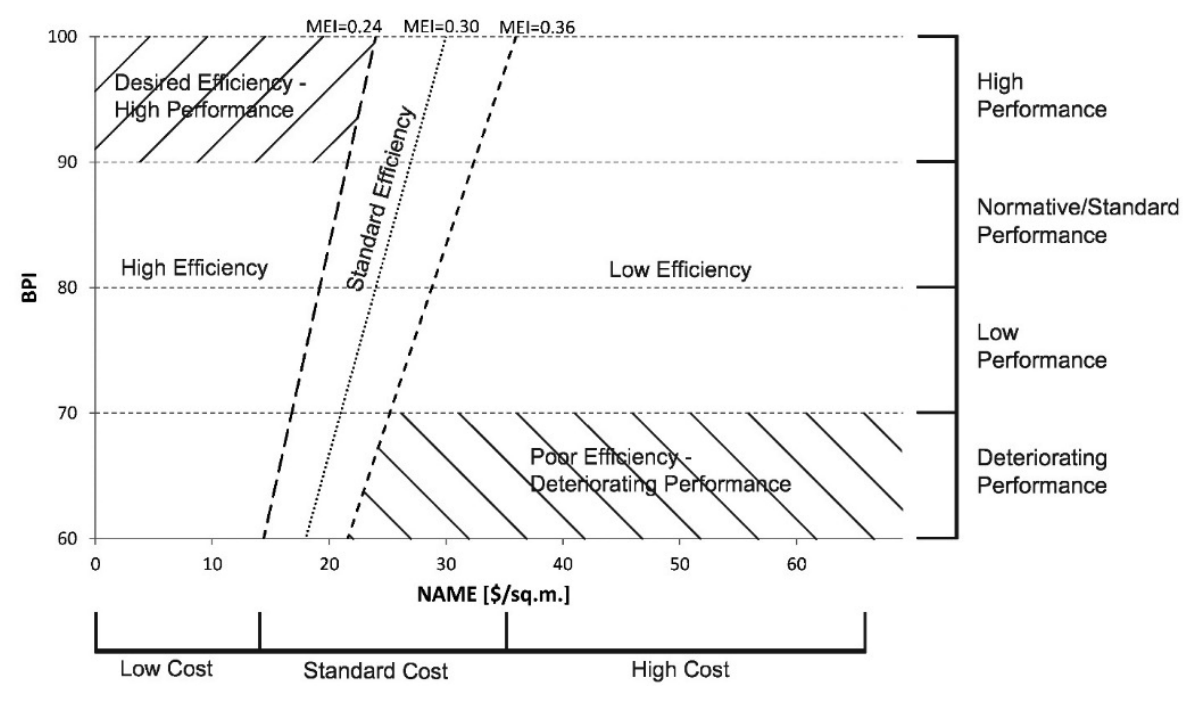

Fig. 2. $M E I$ evaluation in terms of NAME-BPI

were interpreted according to the following categories:

- $M E I<0.24$ indicates high efficiency where the resources are effectively utilized, or where there are few resources for maintenance, or both.

- $0.36 \geq M E I \geq 0.24$ expresses a reasonable range of maintenance efficiency, where the lower limit indicates good maintenance efficiency while the upper limit indicates low maintenance efficiency and/or a lack of resources.

- $M E I>0.36$ indicates high input relative to actual performance. Such a high indicator value may reflect high maintenance expenditure, low physical performance, or a combination of these two extreme situations.

Once the maintenance efficiency of the building has been assessed through the MEI, the facility manager can then evaluate the efficiency level of maintenance management. Figure 2 presents a graph where the $M E I$ of the facility is evaluated in terms of NAME-BPI, which allows an explicit and clear definition of the different zones of efficiency/ performance. Different decisions can be triggered by the results depending on the actual efficiency/ performance of the facility under analysis; an example of the application of this model is given in the case study presented below.

This framework provides unequivocal inference logic for the performance and maintenance management of clinics.

\subsubsection{Maintenance sources ratio (MSR)}

Outsourcing constitutes an alternative to the implementation of maintenance activities by in-house employees who require on-going management. Outsourcing can serve as a means for the execution of seasonal preventive maintenance work, as well as rehabilitation, renovation, and replacement activities. This parameter reflects the mix of internal and external maintenance resources, and expresses the extent of outsourcing (in \%) out of the total labor resources allocated for maintenance of the clinic. In previous studies, it was reported that outsourcing may contribute to savings of $10 \%$ compared to inhouse provision of maintenance services (Domberger, Jensen 1997). In a research study on hospitality facilities, Chan et al. (2001) defined the optimal proportion of outsourced maintenance works as $54.4 \%$. For clinics it is possible to define a proportion of $60 \%$ of outsourcing as giving a guarantee of a solid balance under standard service conditions.

\subsubsection{Managerial span of control (MSC)}

In the FM context, this indicator refers to the number of facilities under the supervision of a single facility manager. Depending on the situation, this KPI can also express the number of employees who are directly subordinate to the manager in the maintenance department. A previous study of managerial span of control (MSC) in the construction industry (Laufer, Shohet 1991) reported that the $M S C$ affects the way managers divide their time and consequently the performance of the organization. Since the $M S C$ affects the level of indirect costs this parameter must be adjusted according to the prevailing conditions. In the present research study, the optimal value of the $M S C$ will depend on the dimensions of the facilities under the control of the facility manager and will need to be defined case by case. For instance, in large facilities that are geographically dispersed, the desired $M S C$ would be eight. 


\subsection{The definition of maintenance priorities}

After the performance of the building's systems has been assessed, it is then necessary to define the priorities of the maintenance work according to (a) the present state of the systems (b) the objectives of the organization and (c) the possible risks due to failures of these systems. This process of defining maintenance priorities can be carried out using the Boston quadrant matrix (see Fig. 3) where the vertical axis is the performance of the system/component expressed by the BPI and the horizontal axis is the potential risk level expressed in a scale from 0 to 5 . The risk level should be defined by the organization's facility manager in consultation with the contractor's superintendent or engineer and should be based on the analysis of the possible failure scenarios for each component. For example, the fire extinguishing system should have a potential risk level of 5 due to possible vulnerabilities in the event of fire in the building. On the other hand, the exterior envelope should have a potential risk level between 3 and 4 because, even if the level of possible safety risks to the users is very low, a failure, for example, in the roof could allow moisture to penetrate the building, which could then lead to failures in other systems, such as the electrical system or the interior finishing.

Table 1 depicts an example of potential risk level assessment used for setting the priority in the case study (see section 5.2).

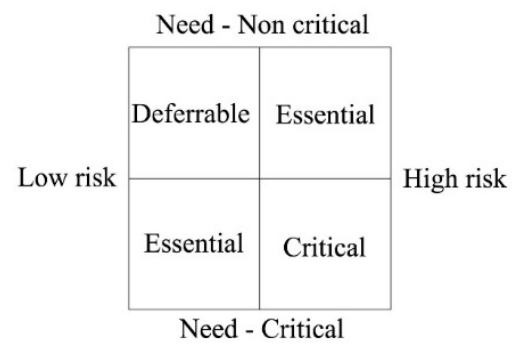

Fig. 3. Boston quadrant matrix

Table 1. Example of potential risk level assessment for the building's systems

\begin{tabular}{ll}
\hline Building's system & $\begin{array}{l}\text { Potential } \\
\text { risk level }\end{array}$ \\
\hline Structure & 5.0 \\
Exterior envelope & 3.0 \\
Interior finishing & 2.0 \\
Electricity system & 4.0 \\
Water and sewage & 3.0 \\
HVAC & 3.0 \\
Fire extinguishing system & 5.0 \\
Information and Communication & 2.5 \\
Technology (ICT) & \\
Elevators & 4.0 \\
\hline
\end{tabular}

\section{APPLICATION AND FINDINGS}

This paragraph presents the research findings in two phases: (1) identification of the sample population used for profiling the clinics in the sample (2) analysis of a case-study that can be used for the implementation of the KPIs in tactical and strategic levels of maintenance management and for the validation of their applicability.

\subsection{The sample population}

Table 2 shows the profile of the sample of 42 selected clinics. The mean floor area of the clinics is $1,214 \mathrm{~m}^{2}$. The respective mean age coefficient for the buildings is 0.88 reflecting the reduced need for resources in the maintenance of facilities with a mean age of 11.2 years. The annual number of visitors per $\mathrm{m}^{2}$ representing the density of the clinics is 273 visitors $/ \mathrm{m}^{2}$ per year, where an annual number of 175 visitors $/ \mathrm{m}^{2}$ per year is defined as standard density. In light of the latter finding, we can deduce that the sample of clinics represents facilities that operate under intensive service conditions. The mean annual maintenance expenditure for the maintenance of the clinics in the clinic sample is $\$ 33.20 / \mathrm{m}^{2}$, which amounts to $2.81 \%$ of the annual reinstatement value of the clinics $(\$ 1,180 /$ $\mathrm{m}^{2}$ ). In light of the young age of the clinics in the sample, this level of maintenance is high and may be explained by the intensive service conditions under which the clinics operate. The maintenance sources ratio $(M S R)$ represents a blend of outsourcing and in-house maintenance service provision. The MSR shows that $60.6 \%$ of the services are contracted out. This mix is rationalized by the intensive service conditions of clinics that require a high availability of inhouse maintenance crews to carry out urgent services. The managerial span of control of the clinics' regional facility manager is 7.2 compared with a standard value of 6 . This value is explained by the relatively small size of the facilities. The building performance indicator mean value is 91.0 , which indicates a high performance level for the clinics. The relatively small variance of the parameter indicates its significance. The last parameter - the maintenance efficiency indicator $(M E I)$ - expresses the efficiency with which the maintenance resources are utilized. The mean $M E I$ of 0.40 for the clinic sample indicates that the performance of the facilities is out of the range of the desired value interval (between 0.24 and 0.36 ); the fluctuation in this parameter expresses significant variability in this measure of efficiency. 
Figure 4 shows the distribution in the clinic sample in a two-dimensional space where the independent variable is the normalized annual maintenance expenditure (NAME) and the dependent variable is $B P I$. The three lines represent equilateral lines of efficiency where 0.30 is the expected (standard) level of efficiency, and where the other two lines express the margins of the standard region of efficiency. The distribution shows that only $55 \%$ (23 facilities) in the clinic sample fall between the upper and lower margins of the standard region of efficiency. This distribution validates the predicted values deduced from the development of this parameter. Facilities that are close to the left margin line $(M E I=0.24)$ exemplify high efficiency in the use of maintenance resources, whereas facilities close to or beyond the right $M E I=0.36$ margin line require (a) further analysis as to the sources of inefficiency and (b) the development of an efficiency improvement program.

Figure 5 presents the performance for each building's system in the clinic sample. $P_{n}=90$ de- fines the threshold level of performance required for a clinic according to the HMO's maintenanceperformance policy. Figure 6 depicts (1) the minimum and the maximum values of performance of each system and (2) the identification of the second and third quartiles of the clinic sample.

Table 2. Summary of the parameters of the clinic sample

\begin{tabular}{|c|c|c|}
\hline & Mean & $\begin{array}{l}\text { Standard } \\
\text { deviation }\end{array}$ \\
\hline Floor area $\left[\mathrm{m}^{2}\right]$ & 1,214 & 924 \\
\hline Age [years] & 11.2 & 7.5 \\
\hline Annual number of visitors $/ \mathrm{m}^{2}$ & 273 & 155 \\
\hline $\begin{array}{l}\text { Annual maintenance expenditure - } \\
\text { AME }\left[\$ / \mathrm{m}^{2}\right]\end{array}$ & 33.2 & 16.4 \\
\hline Managerial span of control - MSC & 7.2 & 3.2 \\
\hline Maintenance sources ratio - MSR & $60.6 \%$ & $17.5 \%$ \\
\hline Building Performance Indicator - BPI & 91.0 & 5.7 \\
\hline $\begin{array}{l}\text { Normalized annual maintenance } \\
\text { expenditure - NAME }\left[\$ / \mathrm{m}^{2}\right]\end{array}$ & 36.3 & 19.2 \\
\hline $\begin{array}{l}\text { Maintenance efficiency indicator - } \\
\text { MEI }\end{array}$ & 0.40 & 0.21 \\
\hline
\end{tabular}

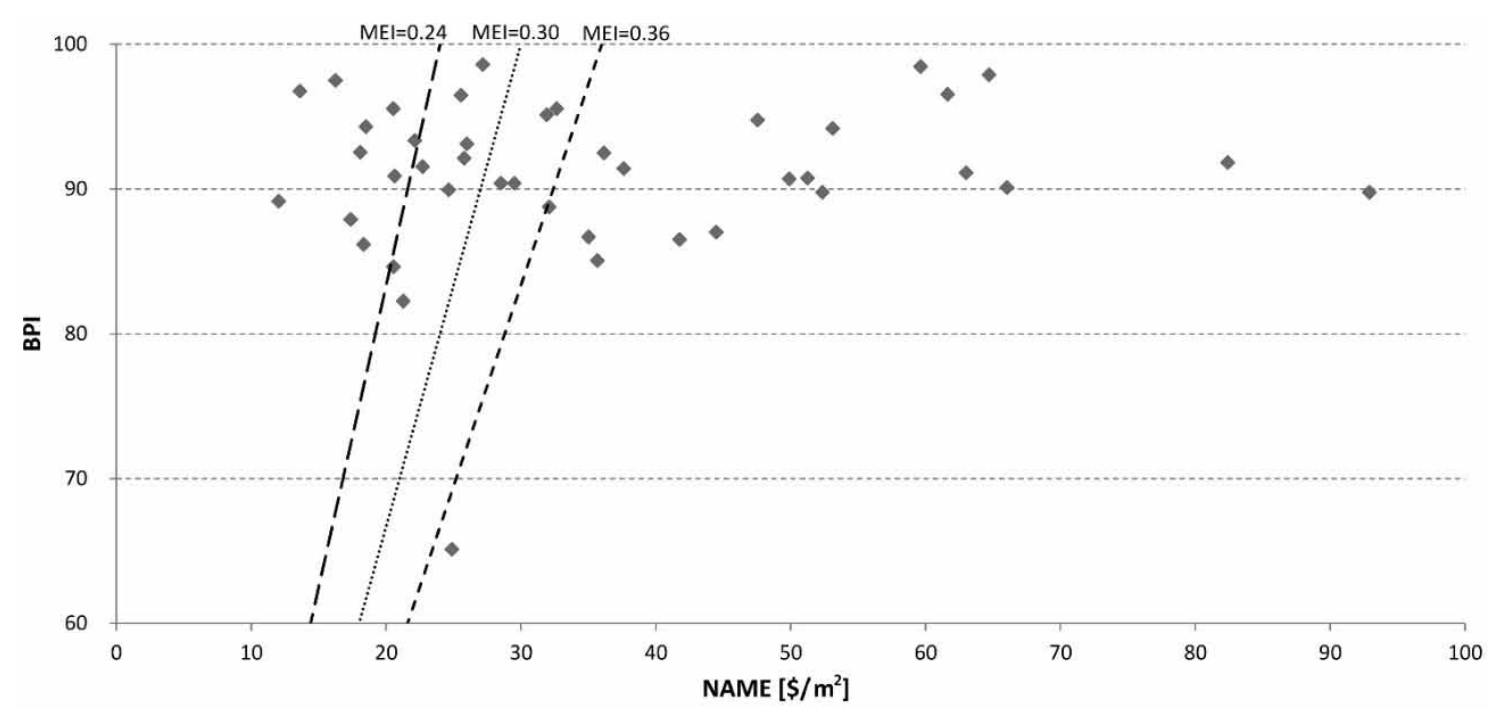

Fig. 4. Building performance indicator against normalized annual maintenance expenditure for the clinic sample

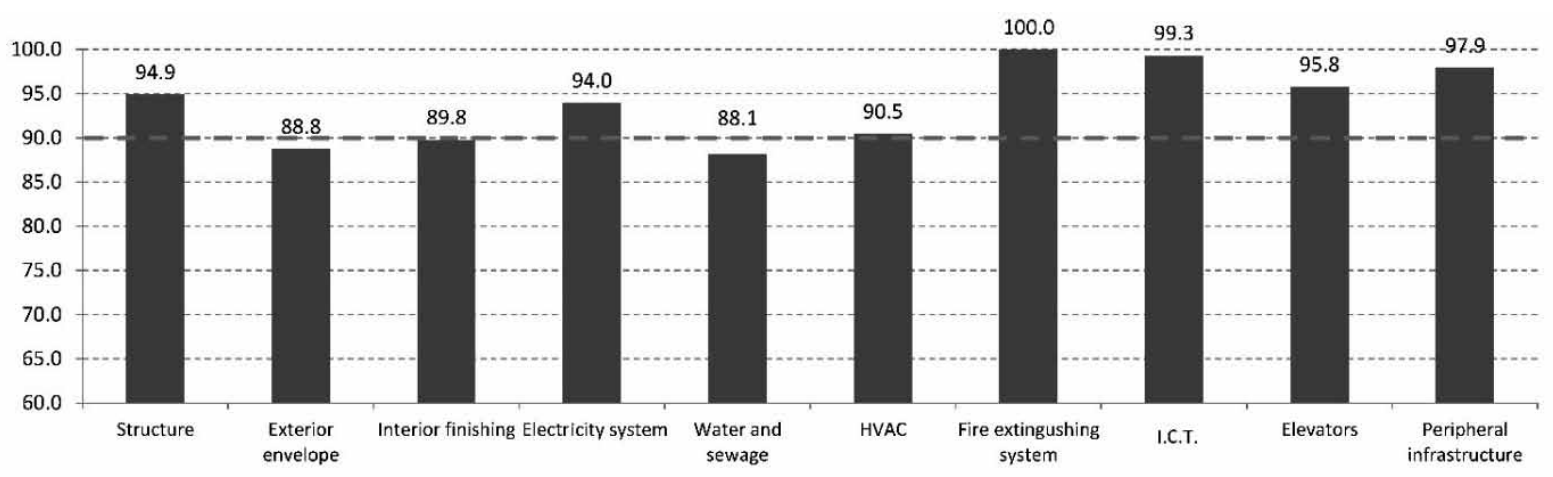

Fig. 5. Mean value of performance of each building's system in the clinic sample 


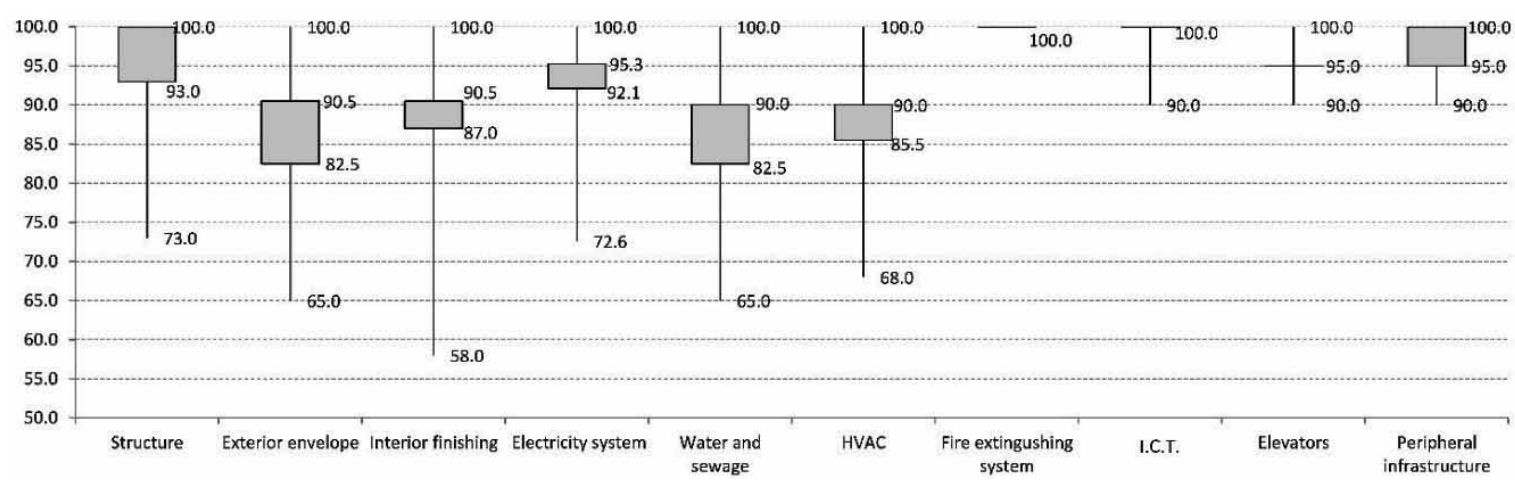

Fig. 6. Minimum, maximum, second and third quartile value of performance for each system

The analysis shows that the fire extinguishing system, ICT, elevators and peripheral infrastructures are in a good state; the performance of all the clinics participating in the sample was found to be above 90 points. Furthermore, the structure and electricity system distribution indicates that the second quartile was above the desired level of 90 points, which means that more than the $75 \%$ of the clinics succeeded in meeting the desired level of performance. Only in a few cases did the $P_{n}$ value not meet the minimum requirement level. The exterior envelope, interior finishing, the water and sewage and HVAC systems all have a mean value that is under or very close to the threshold value. Analyzing Figure 6, it is possible to see that, with regard to these systems, almost $75 \%$ of the clinics have a performance level that is less than the desired value.

\subsection{Case study}

An application of the previously defined KPIs is presented in this section. The case study under analysis is a community clinic located in Rosh Haayin, which is a district in central Israel. It has a conventional two-story reinforced concrete structure; the exterior envelope is clad with natural limestone and has aluminum window frames and curtain walls. The air conditioning system is composed of split air conditioning units. The building has a fire detection and fire extinguishing system.

\subsubsection{Analysis}

Table 3 shows how the characteristics of the case study clinic compare to those of the population as a whole. The case study has a built-up floor area of $1,200 \mathrm{~m}^{2}$, and can be considered as representative of the whole population, which has a mean value of $1,214 \mathrm{~m}^{2}$ The structure is relatively young (7 years old). The number of visitors is $321 / \mathrm{m}^{2}$ per year, which is higher than the mean value and gives
Table 3. Comparison of the characteristics of the whole clinic sample with those of the case study

\begin{tabular}{lll}
\hline & $\begin{array}{l}\text { Case } \\
\text { study }\end{array}$ & $\begin{array}{l}\text { Clinic } \\
\text { sample }\end{array}$ \\
\hline Floor area $\left[\mathrm{m}^{2}\right]$ & 1,200 & 1,214 \\
Age [years] & 7.0 & 11.2 \\
Annual number of visitors $/ \mathrm{m}^{2}$ & 321 & 273 \\
$\begin{array}{l}\text { Annual maintenance expenditure - } \\
\text { AME [ } \$ \mathrm{~m}^{2} \text { ] }\end{array}$ & 31.2 & 33.2 \\
$\begin{array}{l}\text { Managerial span of control - MSC } \\
\text { Maintenance source ratio - MSR }\end{array}$ & 5.0 & 7.2 \\
$\begin{array}{l}\text { Building Performance Indicator - BPI } \\
\text { Normalized annual maintenance }\end{array}$ & 86.7 & $61.0 \%$ \\
$\begin{array}{l}\text { expenditure - NAME }\left[\$ / \mathrm{m}^{2} \text { ] }\right. \\
\text { Maintenance efficiency indicator - MEI }\end{array}$ & 0.40 .0 & 36.3 \\
\hline
\end{tabular}

a density significantly higher than the standard value of 175 visitors $/ \mathrm{m}^{2}$ per year. This parameter indicates intensive use of the structure and the requirement for an intensive service regime for the components of the various systems in the building, such as interior finishing, exterior envelope and electro-mechanical systems. Despite the intensive use of the building the $A M E$ is $\$ 31.20 / \mathrm{m}^{2}$ per year, which is $5.9 \%$ lower than the mean value of the clinic sample because of the relatively young age of the facility. The intensive use of the clinic is reflected in the low BPI as compared with the other clinics in the sample. Figure 7 presents a comparison of the performance of the case study building systems with the mean values of the clinic sample. It can be seen that the lower performance level is due mainly to three systems: exterior envelope, interior finishing and the electro-mechanical systems (electricity, ICT and elevators). The managerial span of control has a value of 5 while the maintenance source ratio of $60 \%$ is similar to the mean value of the entire clinic sample. Finally, the $M E I$ of the case study exceeds the desired range (0.24-0.36) but is consistent with that of the clinics 


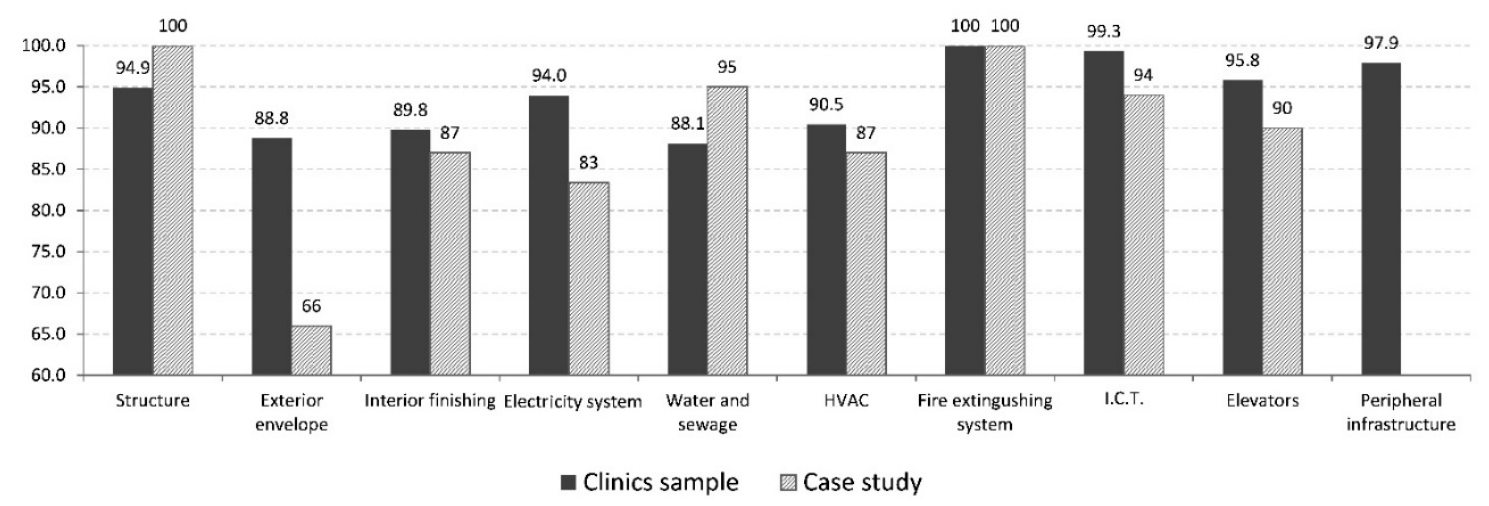

Fig. 7. Comparison of the building system performance: the clinic sample versus the case study

in the clinic sample; it should also be noted that the value of 0.40 is identical to the mean value of the sample. This indicates redundancy of resources at a level of $30 \%$ as compared with the median of the desired range.

\subsubsection{Deduction of corrective actions}

From the analysis of the KPIs of the case study, the following conclusions can be deduced:

- The level of performance of the clinic is not compatible with the annual cost of maintenance. The low efficiency as defined by the $M E I$ is related to the poor performance of certain systems such as the building envelope, electricity, HVAC and the interior finishing, as well as to the presence of redundant resources.

- The $M S C$ value of 5 should be increased to $7-8$ clinics, which should not affect the performance level of the maintenance management. Figure 8 presents the efficiency of maintenance activity in the case study clinic. It can be seen that the clinic is not located within the desired standard range of efficiency and, from the ratio between the $M E I$ and the desired MEI, it can be deduced that efficiency could be improved by $33 \%$. This upgrading could be realized by raising the performance level of the facility from a $B P I$ of 86.7 to a BPI of 90 (with the focus on maintenance of the exterior envelope, the interior finishing and the electro-mechanical systems and on increased preventive maintenance for these systems) and by reducing the NAME from $\$ 35 / \mathrm{m}^{2}$ per year to $\$ 27 / \mathrm{m}^{2}$ per year (that is, by increasing the $M S C$ and reducing breakdown maintenance). After the desired (standard) performance level has been reached, the next objective should be attainment of the optimal efficiency level, where $M E I=0.24$ (with $B P I=95$ and $N A M E=\$ 20.80) . \triangle N A M E$ and $\triangle B P I$ are the marginal benefits in terms of the cost-reduction and performance of the deduced policy.

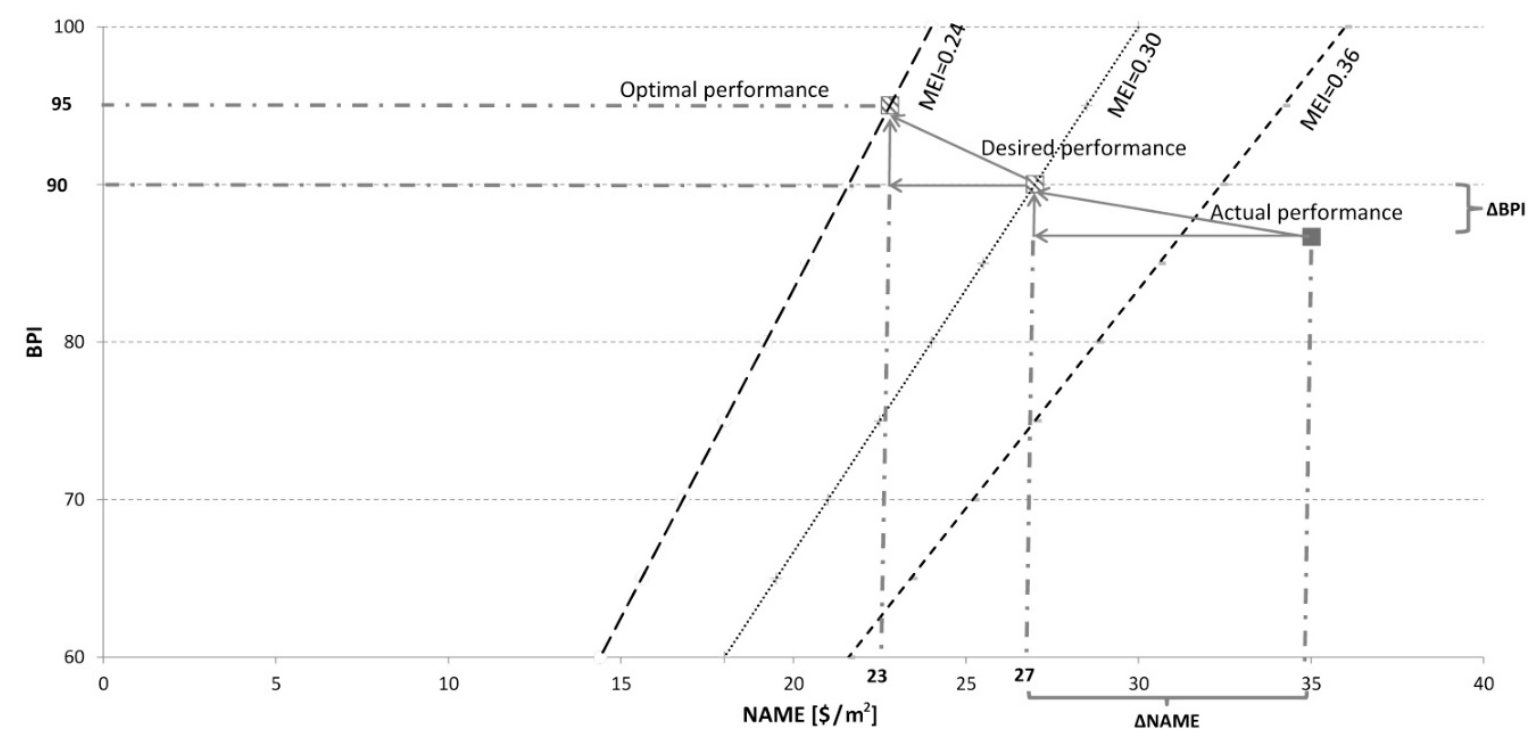

Fig. 8. Actual and desired performance of the clinic and corrective actions 


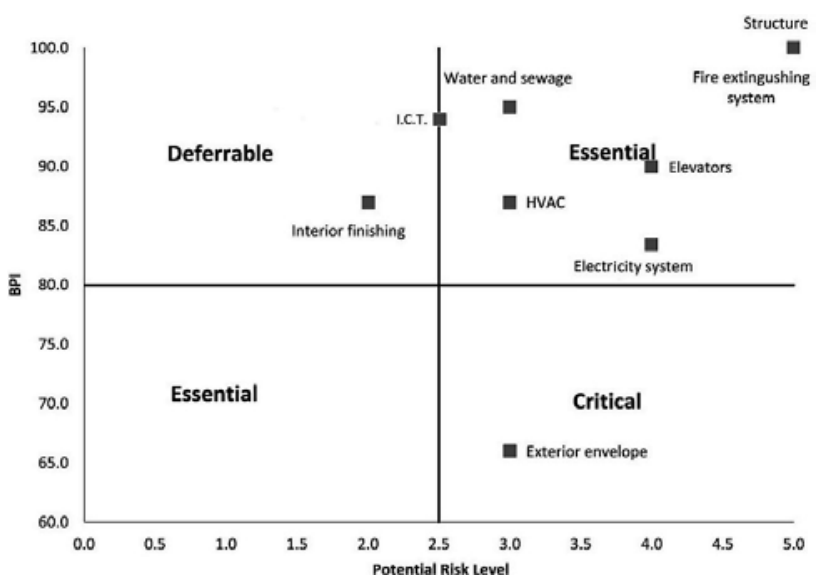

Fig. 9. Boston quadrant matrix of the systems of the case study

- According to analysis with the Boston quadrant matrix, priority should be given to the preventive maintenance of the elevators, the HVAC and electrical systems and especially the exterior envelope (see Fig. 9).

\section{CONCLUSION AND DISCUSSION}

The objectives of the research study were to implement a set of KPIs in a sample of clinics in order to:

- Assess the actual performance of the facilities.

- Perform intra- and inter-organization benchmarking.

- Set policy at the strategic and tactical level of management.

- Set priority in the maintenance work.

The KPIs analyzed and applied in the present research study seek to create a body of knowledge for the continuous improvement at the strategic and tactical levels of maintenance management, in the health sector in general and in community clinics in particular. This improvement can be realized through the use of a set of seven key performance indicators for clinic maintenance. These include age and density coefficients, expressing the effects of age and service conditions on the maintenance needs. Annual maintenance expenditure and maintenance sources ratio outline the profiles of maintenance expenditure and service provision. The managerial span of control measures the effectiveness with which the managerial resources are utilized, the building performance indicator expresses the performance level of the clinic, and the maintenance efficiency indicator indicates the effectiveness level at which the resources are utilized.

The KPIs were implemented in a framework where a constant improvement can be obtained through the application of a continuous cycle of: strategy definition (policy setting and priorities definition), work plan and execution, performance measurement and benchmarking, and analysis.

Application of the KPIs to the sample of clinics revealed that only $55 \%$ of the clinics operated at the desired level of efficiency and that this low performance level was due to both improper maintenance management and the overall low performance level of the buildings' systems. Due to the intensive service regime of the clinics, which were characterized by a higher than standard number of visitors $/ \mathrm{m}^{2}$ per year, low levels of performance were more closely examined in four systems: exterior envelope, interior finishing, water and sewage, and HVAC systems. Almost $75 \%$ of the clinics have a performance level that is lower than the desired level for these systems $\left(P_{n}=90\right)$. This data suggests the need for a redefinition of maintenance policy, and for a focusing of attention on preventive maintenance for those systems which are exposed to intensive wear and tear. The results of the changed policy should be an improvement in performance and a decrease in the number of system breakdowns, which would mean a reduction in maintenance costs. Finally a tool for setting priority in maintenance work was demonstrated and applied. The method presented should be applied as a cycle in order to obtain a continuous improvement of the performance and efficiency of the facility.

The case study presented was chosen in order to demonstrate the comprehensive nature of the application and to validate the method. In the case study the KPIs were implemented and the performance of the building assessed and benchmarked. The benchmarking was carried out both throughout the facility as a whole and between the systems within the building. After an analysis of the performance and efficiency, the corrective actions of the maintenance policy and the priorities of the maintenance plan were defined.

As stated above, one of the strong points of a public organization (such as HMOs) is the large number of similar buildings owned. A further development resulting from the findings of the research study should be the creation of a common database for all the facilities. This could lead to substantial improvements in performance through a sharing of knowledge (such as the identification of the most effective maintenance actions for each system's components) in order to encourage continuous improvement in the performance of the clinics. 
The proposed framework may be integrated as a maintenance and performance management module in the HMOs` ERP system.

\section{ACKNOWLEDGMENT}

The authors express their gratitude to the Israel National Institute for Healthcare Policy for the generous suport in this research, under grant $72 / 2003$.

\section{REFERENCES}

Ali, M.; Mohamad, W. M. N. B. W. 2009. Audit assessment of the facilities maintenance management in a public hospital in Malaysia, Journal of Facilities Management 7(2): 142-158.

https://doi.org/10.1108/14725960910952523

Amaratunga, D.; Baldry, D. 2002a. Performance measurement in facilities management and its relationships with management theory and motivation, $\mathrm{Fa}$ cilities 20(10): 327-336.

https://doi.org/10.1108/02632770210443009

Amaratunga, D.; Baldry, D. 2002b. Moving from performance measurement to performance management, Facilities 20(5/6): 217-223. https://doi.org/10.1108/02632770210426701

American Hospital Association. 2010. Chartbook 2010 Chapter 3: Utilization and volume [online]. American Hospital Association, United States, Chicago. Available at: http://www.aha.org/research/reports/tw/chartbook/2010/chapter3.pdf [accessed 7 September 2015].

American Hospital Association. 2014. Chartbook: Trends affecting hospitals and health systems 2000-2013 [online]. American Hospital Association, United States, Chicago. Available at: http://www.aha.org/ research/reports/tw/chartbook/index.shtml [accessed 7 February 2015]

Campbell, J. D. 1995. Outsourcing in maintenance management, Journal of Quality in Maintenance Engineering 1(3): 18-24. https://doi.org/10.1108/13552519510096369

Centraal Bureau voor de Statistiek. 2014. Hospital admissions 1993-2013 [online]. Available at: http:// www.cbs.nl/en-GB/menu/themas/gezondheid-welzijn/ cijfers/extra/2010-ziekenhuisopname.html [accessed 7 February2015]

Chan, K. T.; Lee, R. H. K.; Burnett, J. 2001. Maintenance performance: a case study of hospitality engineering systems, Facilities 19(13/14): 494-503. https://doi.org/10.1108/02632770110409477

Ciarapica, F. E.; Giacchetta, G.; Paciarotti C. 2008. Facility management in the healthcare sector: analysis of the Italian situation, Production Planning \& Control 19(4): 327-341. https://doi.org/10.1080/09537280802034083

Cingolini, F.; Fedele, L.; Villa, A. N. 2008. Managing facilities under the multi-service result-oriented approach: some insights coming from the field in Italy,
Production Planning and Control 19(4): 321-326. https://doi.org/10.1080/09537280802034075

Domberger, S.; Jensen, P. 1997. Contracting out by the public sector: theory, evidence, prospects, Oxford Review of Economic Policy 13(4): 67-78. https://doi.org/10.1093/oxrep/13.4.67

Federal Statistical Office Germany. 2014. Hospitals: Medical facilities, hospital beds and movement of patient 1991-2013 [online]. Available at: https://www. destatis.de/EN/Factstableures/SocietyState/Health/ Hospitals/Tables/HospitalsYears.html [accessed 7 February 2015]

Gallagher, M. 1998. Evolution of facilities management in the health care sector, in P. Harlow (Ed.). Construction Papers 86. The Chartered Institute of Building, 1-8.

Gelnay, B. 2002. Facility management and the design of Victoria Public Hospitals, in Proceedings of the CIB Working Commission 70 - Facilities Management and Asset Maintenance Global Symposium 2002, 18-20 September 2002, Glasgow, Scotland, 525-545.

Grussing, M. N.; Liu, L. Y. 2014. Knowledge-based optimization of building maintenance, repair, and renovation activities to improve facility life cycle investments, Journal of Performance of Constructed Facilities 28(3): 539-548. https://doi.org/10.1061/(ASCE) CF.1943-5509.0000449

Islam, F.; Rahman, A.; Halim, A.; Eriksson, C.; Rahman, F.; Dalal, K. 2015. Perceptions of health care providers and patients on quality of care in maternal and neonatal health in fourteen Bangladesh government healthcare facilities: a mixed-method study, BMC Health Services Research 15: 237. https://doi.org/10.1186/s12913-015-0918-9

Israel Standards Institution. 2010. Israel Standard 1525 part 3: Buildings Maintenance: Non - Residential Buildings and their nearby surroundings - service systems. Tel Aviv, Israel.

Jones, K.; Sharp, M. 2007. A new performance-based process model for built asset maintenance, Facilities 25(13/14): 525-535.

https://doi.org/10.1108/02632770710822616

Kakabadse, A.; Kakabadse, N. 2005. Outsourcing: current and future trends, Thunderbird International Business Review 47: 183-204. https://doi.org/10.1002/tie.20048

Langston, C.; Lauge-Kristensen, R. 2002. Strategic management of built facilities. Oxford: ButterworthHeinemann.

Laufer, A.; Shohet, I. M. 1991. Span of control of the construction foreman: situational analysis, Journal of Construction Engineering and Management 117(1): 90-105. https://doi.org/10.1061/(ASCE)07339364(1991)117:1(90)

Lavy, S.; Garcia, J. A.; Dixit, M. K. 2010. Establishment of KPIs for facility performance measurement: review of literature, Facilities 28(9/10): 440-464. https://doi.org/10.1108/02632771011057189

Lavy, S.; Garcia, J. A.; Dixit, M. K. 2014a. KPIs for facility's performance assessment, Part I: identification and categorization of core indicators, Facilities 32(5/6): 256-274. https://doi.org/10.1108/F-09-2012-0066 
Lavy, S.; Garcia, J. A.; Dixit, M. K. 2014b. KPIs for facility's performance assessment, Part II: identification of variables and deriving expressions for core indicators, Facilities 32(5/6): 275-294.

https://doi.org/10.1108/F-09-2012-0067

Lega, F.; Marsilio, M.; Villa, S. 2013. An evaluation framework for measuring chain performance in the public healthcare sector: evidence from the Italian NHS, Production Planning \& Control 24(10-11): 931-947. https://doi.org/10.1080/09537287.2012.666906

Lennerts, K. 2009. Investing in hospitals of the future, Chapter 9. World Health Organization, UK, 167-189.

Lützkendorf, T.; Speer, T.; Szigeti, F.; Davis, G.; le Roux, P.; Kato, A.; Tsunekawa, K. 2005. A comparison of international classifications for performance requirements and building performance categories used in evaluation methods, in Proceedings of the $11^{\text {th }}$ Joint CIB International Symposium Combining Forces - Advancing Facilities Management and Construction through Innovation. Technical Research Centre of Finland (VTT) / Association of Finnish Civil Engineers (RIL), 13-16 June 2005, Helsinki, Finland, 61-80.

Marquez, A. C.; Gupta, J. N. F. 2006. Contemporary maintenance management: process, framework and supporting pillars, Omega 34(3): 313-326. https://doi.org/10.1016/j.omega.2004.11.003

Melin, A.; Granath, J. A. 2004. Patient focused healthcare: an important concept for provision and management of space and services to the healthcare sector, Facilities 22(11/12): 284-289.

https://doi.org/10.1108/02632770410561277

Muchiri, P. N.; Printelon, L.; Gelders, L.; Martin, H. 2011. Development of maintenance function performance measurement framework and indicators, International Journal of Production Economics 131(1): 295-302. https://doi.org/10.1016/j.ijpe.2010.04.039

Muchiri, P. N.; Printelon, L.; Martin, H.; De Mayer, A. 2010. Empirical analysis of maintenance performance measurement in Belgian industries, International Journal of Production Research 48(20): 59055924. https://doi.org/10.1080/00207540903160766

Pati, D.; Park, C.; Augenbroe, G. 2010. Facility maintenance performance perspective to target strategic organizational objectives, Journal of Performance of Constructed Facilities 24(2): 180-187. https://doi. org/10.1061/(ASCE)CF.1943-5509.0000070

Payne, T.; Rees, D. 1999. NHS facilities management: a prescription for change, Facilities 17(7/8): 217-221. https://doi.org/10.1108/02632779910270159

Pullen, S.; Atkinson, D.; Tucker, S. 2000. Improvements in benchmarking the asset management of medical facilities, in Proceedings of the International Symposium on Facilities Management and Asset Maintenance, 15-17 November 2000, Brisbane, Australia, 265-271.

Reiling, J.; Hughes, R.; Murphy, M. 2008. The impact of facility design on patient safety, Chapter 28. Patient safety and quality: an evidence-based handbook for nurses, Agency for Healthcare Research and Quality, Rockville, USA.

Shohet, I. M. 2003. Building evaluation methodology for setting maintenance priorities in hospital buildings, Construction Management and Economics 21(7): 681692. https://doi.org/10.1080/0144619032000115562

Shohet, I. M.; Lavy, S. 2004a. Development of an integrated healthcare facilities management model, $\mathrm{Fa}$ cilities 22(5/6): 129-140.

https://doi.org/10.1108/02632770410540342

Shohet, I. M.; Lavy, S. 2004b. Healthcare facilities management - state of the art review, Facilities 22(7/8): 210-220. https://doi.org/10.1108/02632770410547570

Shohet, I. M.; Lavy-Leibovich, S.; Bar-On, D. 2003. Integrated maintenance management of hospital buildings, Construction Management of Economics 21(2): 219-228.

https://doi.org/10.1080/0144619032000079734

Statistics Denmark. 2014. Upartisk og objektiv statistik til samfundet. IND03: Admissions, bed-days and hospital patients by region, age and sex [online]. Available at: http://www.statbank.dk/IND03 [accessed 7 February 2015]

Stichler, J. F.; Ecoff, L. 2009. Joint optimization merging a new culture with a new physical environment, Journal of Nursing Administration 39(4): 156-159. https://doi.org/10.1097/NNA.0b013e31819c9b95

Straub, A. 2009. Cost savings from performance-based maintenance contracting, International Journal of Strategic Property Management 13(3): 205-217. https://doi.org/10.3846/1648-715X.2009.13.205-217

Straub, A.; Van Mossel, H. J. 2007. Contractor selection for performance-based maintenance partnerships, International Journal of Strategic Property Management 11(2): 65-76.

Talib, Y.; Rajagopalan, P.; Yang, R. J. 2013. Evaluation of building performance for strategic facilities management in healthcare, Facilities 31(13/14): 681-710. https://doi.org/10.1108/f-06-2012-0042

Tulla, K.; Hekkanen, M.; Mottonen, V. 2002. Development of an asset maintenance strategy for a hospital complex, in Proceedings of the CIB Working Commission 70 - Facilities Management and Asset Maintenance Global Symposium 2002, 18-20 September 2002, Glasgow, Scotland, 546-553.

Ulrich, R.; Quan, X. 2004. The role of the physical environment in the hospital of the $21^{\text {st }}$ century: a oncein-a-lifetime opportunity, Report to the Center for Health Design for the Designing the $21^{\text {st }}$ Century Hospital Project.

Van Horenbeek, A.; Pintelon, L. 2014. Development of a maintenance performance measurement framework using the analytic network process (ANP) for maintenance performance indicator selection, Omega 42(1): 33-46. https://doi.org/10.1016/j.omega.2013.02.006

Yik, F. W. H.; Lai, J. H. K. 2005. The trend of outsourcing for building services operation and maintenance in Hong Kong, Facilities 23(1/2): 63-72. https://doi.org/10.1108/02632770510575901 